\title{
RAPID DEPLOYMENT OF SIMULATION MODELS FOR BUILDING CONSTRUCTION APPLICATIONS
}

\author{
Gunnar Lucko \\ Department of Civil Engineering \\ 620 Michigan Avenue NE \\ The Catholic University of America \\ Washington, DC 20064, USA
}

\author{
Kannan Swaminathan \\ Perakath C. Benjamin \\ Knowledge Based Systems, Inc. \\ 1408 University Drive East \\ College Station, TX 77840, USA
}

\author{
Michael G. Madden \\ M. Madden Consulting, LLC \\ 2570 Red Maple Place \\ Melbourne, FL 32935, USA
}

\begin{abstract}
This paper presents a knowledge based approach to increase the use of simulation in the construction industry without its users having to become or hire experts in simulation techniques. The premise of this approach is to use existing process-related schedule information as inputs to create a functioning simulation model with little or no user intervention. It explains analytical capabilities and limitations of schedules and simulation, reviews previous discrete event simulation studies, and discusses integrating knowledge from this domain. It describes the architecture of the WorkSim ${ }^{\circledR}$ system. A case study presents processes of a real construction project. The conceptual and pragmatic feasibility of converting schedules into simulations is tested with its representative sample dataset. Modeling and analyzing this case study establishes the technical viability of the ideas discussed in the paper. Future work will examine challenges to the quality of such models, e.g. their resolution, required resource data, and duration distributions.
\end{abstract}

\section{INTRODUCTION}

The construction industry practice has for too long neglected a valuable tool that has found diverse applications in other industries. Computer process simulation is a versatile modeling and analysis approach that supports critical decision making, particularly for large and complex processes that do not easily lend themselves to direct solutions. Such dynamic models are employed because (a) they can be observed in a controlled environment, (b) they are safer to use than the real process, (c) they are faster than the real process, (d) they replicate the phenomenon of interest and related factors while simplifying or ignoring others to reduce the complexity, cost, and duration of the study, (e) they allow sensitivity analysis, (f) they can be repeated to create many observations for statistical analysis, while a real process often occurs only once, and (g) they allow experimentation with large and complex systems with randomized behavior that otherwise would resist a detailed analysis.

\section{CURRENT NEED}

Despite a wide range of studies in construction process simulation (Hassan and Gruber 2008, Zayed and Halpin 2004, Zayed and Halpin 2001, Ioannou and Martínez 1996) this body of research is rarely applied to construction practice. Lucko et al. (2008) listed important reasons for this disparity, namely the time, cost, and skills required to build and analyze simulation models. Numerous authors previously identified these items (Benjamin et al. 2006, Cates et al. 2002, Son and Wysk 2001), which are key aspects of just one pressing problem - the need to painstakingly learn simulation in its implementation in a particular software application. Even if the subject matter expert (e.g. a construction manager) does not create the model, he or she would still need to spend a significant amount of time with a simulation expert (Lingineni et al. 1995) to share the relevant knowledge of the domain, define the process, and validate that the new model correctly represents the actual process.

\subsection{Construction Industry}

The construction industry is a major contributor to the U.S. economy and "also maintains the most consistent job growth" with 7.7 million employees (5.7\% of total) in 883,000 companies and 1.9 million self-employed persons (all data for 2006, Bureau of Labor Statistics 2008) who generate 5.1\% of the gross domestic product (Bureau of Economic Analysis 2008). It is highly fragmented; "[a]bout $65 \%$ of establishments in the industry employ fewer than 5 people" and over $91 \%$ employ fewer than 20 (Bureau of Labor Statistics 2008). Challenges to adopting innovative technologies are its highly competitive business 
environment and a traditional resistance to change. An urgent need exists to rapidly deliver high quality facilities while reducing their life-cycle costs (Bonnal et al. 2002), i.e. the combined costs of planning, construction, operation, and demolition.

\subsection{Construction Characteristics}

Tatum (1988) classified construction technology according to processes, resources, and constraints. Resources included information, skills, equipment, tools, general conditions, space, energy, and time. They have a specific capacity and productivity and must be balanced in their required versus available amounts. Activities, or tasks, may require several resources that are constrained by available space and by the changing configuration of the growing structure (Lucko et al. 2008). While construction projects are unique in their design and site conditions, repetition in processes can often be identified because materials are usually installed in several different locations. Methods (processes) can be distinguished by means (resources) that are employed and by materials that are either transported or transformed. Typical methods in building construction are:

- Soil and rock: Earthmoving equipment loosens and excavates, loads, hauls, dumps, spreads, and compacts materials.

- Cast-in-place concrete: Formwork and shoring is erected, reinforcement is assembled into cages, ingredients are batched and delivered with mixing trucks, placed with crane buckets or pump trucks, consolidated, finished, and cured under controlled conditions until shoring is removed and formwork is stripped. Precast segments are manufactured, delivered, stored, lifted with cranes, and anchored. Post-tensioning tendons are stressed with hydraulic jacks.

- $\quad$ Steel: Shop-fabricated structural steel members are manufactured, delivered, stored, lifted with cranes, anchored, and connected with bolts or welds. Corrosion protection and fire-retarding coating may be applied before enclosing.

- Masonry: Bricks are delivered on pallets, stored, and transferred to the workface. Mortar is delivered in bags or silos, mixed in drums, and bucketed. Courses of brick are set, insulation and ties are installed, and joints are tooled.

- Wood: Lumber is delivered, stored, cut to size, assembled into frame elements, transferred to the workface, erected, and connected with nails, screws, or bolts. Mechanical and electrical systems, insulation, and paneling is installed.

- Mechanical and electrical systems: Complex systems with pipes and cables for lighting, heating/cooling, ventilation, plumbing, fire protection, communication, and security must be tested before they are enclosed in walls and ceilings.

- $\quad$ Finishing works: Materials (e.g. partition walls, doors, windows, lighting and sanitary fixtures, tiles and carpet) are delivered, stored, transferred to the workface, cut to size if needed, and attached with nails, screws, grout, or sealant. Simulation is ideal to exploit such repetitiveness and identify where any efficiency gains could be realized to save costs.

\subsection{Scheduling Practice}

The objective of scheduling is to develop a feasible and comprehensive plan for timely execution and to control its progress. Creating a schedule is both art and science. The critical path method (CPM) takes its name from the approach of adding deterministic durations along paths of dependency in a network and calculating the longest or 'critical' path that yields the project duration. Such network representation of the schedule is acyclic and has one defined start and finish activity each. It was developed by Kelley and Walker (1959) as a special case of linear programming where starts and finishes are linked by activity durations. CPM features a straightforward algorithm and a clear graphical representation, precedence diagramming (Fondahl 1962). Being contractually required for major government projects (Wickwire and Ockman 1999) due to its acceptance by U.S. courts of law for delay claims (Haney v. United States), it is the de facto industry standard (Galloway 2006b) with wide availability of commercial software (Weaver 2006). It is described in the Project Management Book of Knowledge $\left(\mathrm{PMBOK}^{\circledR}\right)$ by the Project Management Institute and was formally codified by the American National Standards Institute.

\subsection{Scheduling Limitations}

Despite the wide appeal of CPM, its analytical capabilities are rather limited. Its static nature with deterministic 'realistic' durations and dependencies makes it difficult to evaluate alternatives, consider uncertainty, and optimize processes. Performing a time-cost tradeoff analysis and optimizing variable resources, productivities (and accordingly activity durations), and costs requires complete new sets of calculations. Probabilistic uncertainty in durations, dependencies, and resources are arduous to implement. CPM models thus severely lack realism. Lesser-known probabilistic methods like the program evaluation and review technique (PERT) with a three-point duration estimate, which yields the probability of finishing a project in a given duration, and Monte Carlo analysis, which yields the criticality index for each activity based on many stochastic runs, are taught in universities (Galloway 2006a), but, in the experience of these authors, are not used in the current construction practice.

\subsection{Simulation Capabilities}

A discrete event simulation system models a process as "as a chronological list of discrete events" (Lucko et al. 2008), which are defined as point in time when activities start of finish or when resource-holding queues acquire or release resources. The 


\section{Lucko, Swaminathan, Benjamin and Madden}

internal calendar of a simulation engine recognizes only such discrete state changes, skipping over uneventful durations in between. Numerical relationships govern the behavior of the model by defining how its activity durations and probabilistic elements are sampled, how many and which resources are required as conditions for activity starts, how many resources are released upon activity finishes, and how competing starts are resolved with priorities. Once implemented in the computer, the dynamic simulation model can be used for experimentation through systematic variation of its parameters in multiple runs.

\section{SIMULATION APPROACHES}

Construction projects are challenging because they are one-of-a-kind solutions with unique planning and execution phases. Planning includes decisions on means and methods, often between significantly different options (e.g. a structural concrete frame versus a steel frame). It must also include contingencies for uncertainties. Yet even the most meticulous plan cannot anticipate all potential problems in the execution. Changes will inevitably occur and may impact time and cost. It is essential that the best project controls are available for construction managers to analyze their data and optimize project performance.

\subsection{Discrete Event Simulation}

Discrete-event simulation (DES) assumes that a dynamic process can be modeled sufficiently accurately as state changes in a future events list. This significantly reduces the computational effort (Martínez 1996). Entities of the model either consume resources (i.e. activities) or hold resources (i.e. queues). A point in time when an attribute of an entity incurs a state change constitutes an event. Events are starts and finishes of activities, i.e. state changes between active and idle and adding or subtracting resources. Several events can occur at the same time. The structure of models can be represented with activity cycle diagrams (Au and Paul 1994). Models need start and finish conditions in terms of time consumed or resources used. Repetitive processes may only reach a steady throughput with stable statistics after a warm-up period (Martínez 1996). Modern DES systems use random number generators to generate samples from stochastic distributions that describe the system.

DES models help studying complex systems in a dynamic and interactive environment. Computer systems for the simulation of construction operations have been developed over four decades from roots in work flow analysis, queuing theory, Monte Carlo analysis, link-and-node models, and GERT (Halpin 1973). Each new DES system for construction management brought important new impulses, e.g. establishing structural conventions and symbols (Halpin 1973), distinguishing resources and their properties (Chang 1986), expanding types of elements and control over them (Liu 1991), adding hierarchical components (Odeh 1992), or providing an extensible language (Martínez 1996) independent of a graphical representation.

\section{ENHANCING SIMULATION}

Simulation for construction management enables sensitivity analyses, balancing resources, and optimizing the overall performance in terms of its time, cost, or productivity. Recent research enhances its conceptual envelope toward integration with other domains, e.g. interactive augmented reality environments that can also provide rapid support for post-disaster response and mitigation (Kamat and El-Tawil 2007) or through algorithms to communicate from the visualization back to its underlying simulation (Rekapalli and Martínez 2007) so that users can interact with the model in a dynamic, graphical environment.

Simulation and its visualization assist decision makers in better understanding how their complex systems react to changes. Simulation is different from visualization, with which it is often confused in practice. Much attention of the construction industry has been focused on computer-aided design (CAD) visualizations. These convert line drawings into architectural design models with photorealistic views of a future structure. A considerable amount of research examined generating (Aalami 1998) and using CAD models (Fischer and Kam 2002), often as 4D animations (Akbaş 2004). Knowledge based expert systems (Froese 1992) used object-oriented programming, provided hierarchical structures of construction elements (Aalami 1998), and discussed common models (i.e. application-neutral descriptions of construction systems). However, studies at the activity level lacked numerical analysis capabilities and differed from process-level visualization (Kamat 2003).

\subsection{Integration of Knowledge Domains}

The integrated computer-aided manufacturing (ICAM) modeling definition (IDEF) languages has origins in the business and military environment, but is in the public domain as a neutral symbolic system of semantics and syntax (Mayer et al. 1992) to capture verbal process descriptions by domain experts. Other such general process modeling languages exist (Karhu 2001).

The first simulation generator (Oldfather et al. 1966) required manually programming of process information (Paul and Chew 1987). Activity inputs and outputs were used in operations equations but omitted queues and only had generic resources (Yuan et al. 1993). The standard for exchanging product data (STEP) of the International Standardization Organization (ISO) and IDEF were used for process modeling to semantically analyze precast concrete operations (Lee 2004) but lacked simulation capabilities. Work on automated simulation model generation focused on aerospace operations, including 
Space Transportation System (space shuttle) missions (Cates et al. 2002, Steele et al. 2002), their ground processing, which required data mining (Madden et al. 2005), and assembly of the International Space Station (Cates and Mollaghasemi 2005). Simulation were automated for business enterprises (Benjamin et al. 1998) and manufacturing (Waller and Ladbrook 2002).

\subsection{Software Architecture}

WorkSim ${ }^{\circledR}$ is a knowledge based dynamic analysis framework that can target construction applications. Its functions include (a) planning, (b) scheduling, (c) discrete event simulation, and (d) optimization. Its user interface provides a user-friendly way to enter data for new entities, updating their progress status, and making changes that reflect the current state of work. Its main window is divided into two panes. The left pane lists the three primary elements of process templates, resources, and workloads. Users can click on entities to edit their data. The right pane displays windows for working with entities and performing functions. All changes to a project are automatically saved to the database. Figure 1 shows WorkSim ${ }^{\mathbb{B}}$ s architecture.

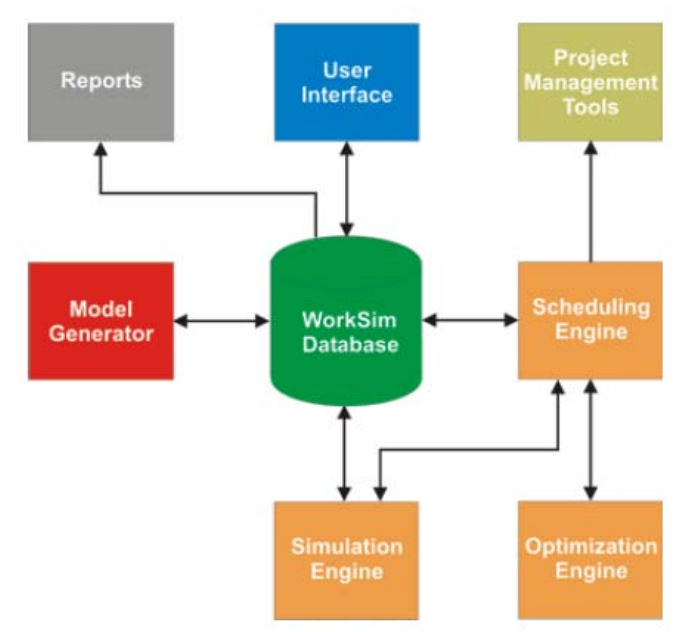

Figure 1. WorkSim ${ }^{\circledR}$ Modeling and Analysis Framework

The discrete simulation engine is used as for schedule generation when activity parameters are stochastic. The optimization engine uses genetic algorithms and simulated annealing to generate optimized schedules for the defined performance criteria. The scheduling engine is a resource-constrained finite capacity module. This engine uses input from the database, i.e. data defined for workload tasks, and the simulation and optimization engines to generate sets of feasible workload schedules.

Schedules generated by the scheduling engine can be exported to widely used software tools, e.g. Microsoft ${ }^{\circledR}$ Project and Microsoft ${ }^{\mathbb{B}}$ Excel. Users can select the destination tool and WorkSim ${ }^{\circledR}$ automatically launches it and loads the scheduling results. Those software tools can use output from the scheduling engine to perform further analyses, e.g. PERT or CPM and resource leveling, and can generate various visualizations of the schedule itself, e.g. Gantt bar charts and network diagrams.

Reports help focus the user's attention on specific findings for analyzing results and pinpointing areas where schedule times and resource allocations can be improved. Many different types are available through a menu, including those that focus on resource usage by tasks and flow times, i.e. the duration that is required to complete a set of tasks as per the precedence and hierarchical constraints, process templates, and task data. Reports can also be exported as HTML or as text files.

\section{CASE STUDY}

Data from a completed construction project of a large office building in the Mid-Atlantic region of the U.S. were obtained by the authors. They received written permission to use the data for research purposes while maintaining confidentiality about the source. Data included a detailed construction schedule plus architectural and structural plan drawings. To augment these data the authors interviewed managerial staff of the contracting company and used a written questionnaire to clarify the construction process in general and resource usage in specific. Resource data were typed to be merged with the electronic data.

\subsection{Project Description}

The project consisted of a nine floor class A office building with a gross area of 16,700 square meters (180,000 sq. $\mathrm{ft}$.). It had a corner tower and penthouse mechanical room with cooling tower. It had three and one half (due to sloping terrain) levels of 


\section{Lucko, Swaminathan, Benjamin and Madden}

underground parking. One basement floor contained the central plant, mechanical and electrical rooms, and storage rooms. The first floor had a larger height to accommodate 1,100 square meters $(12,000 \mathrm{sq}$. ft.) of retail space, a lobby with mail room, and a loading dock. The structural system used reinforced concrete columns carrying unbonded, post-tensioned concrete slabs for bays of 6 by 12 meters (20 by 40 feet) wherein tenants created offices with metal stud framing and drywall partitions. A service core added stiffness to the structural frame. It contained two stairwells, three regular and one service elevator, and two garage shuttle elevators that only reached to the first floor, a pair of bathrooms, and service rooms and closets. The façade were glass windows set into precast concrete spandrel and column cover panels plus natural stone accents on the first floor. Choosing a completed project enables a comprehensive comparison of as-planned with as-built operations, of which this paper presents only the first part. Future research will continue the analysis of this interesting and data rich project.

\subsection{Construction Process}

Construction mobilized by setting up site installations, e.g. the perimeter fence, office trailer, and erosion barriers. Backhoes excavated. The excavation was secured by shoring that was held by three tiers of drilled and stressed tiebacks. A ramp was built to transport materials and equipment. Footings for the tower crane were excavated and built of reinforced concrete that was placed by pump truck. Reinforced concrete spread footings for the building were built in the same manner, but materials were also delivered by tower crane. Drainage pipes in filter fabric were installed underneath the future building and at its perimeter, followed by a compacted sub-grade, gravel layer, vapor barrier, and the reinforced concrete slab. The reinforced concrete basement walls were protected with waterproofing and drainage material. Reinforced concrete slabs were built in several 'pours' by tower crane on top of falsework. It was only removed after the slabs had hardened so that the floor on top could be built before the one below it was at design strength. Above the first floor the structural system changed to cast-inplace post-tensioned concrete slabs. This eliminated beams for a larger floor clearance. The tower crane was dismantled after all concrete had been placed, mechanical equipment had been lifted onto the roof, and the precast façade had been installed.

After the structural frame had been erected, the first three floors of precast panels were installed by mobile crane, spiraling upward through the directions of the compass. The tower crane lifted the remaining panels into place before perimeter insulation, studs, and windows were installed. Afterwards, the façade was caulked from a hanging scaffold. The close-in of the weather-resistant skin of the building formed important milestones for interior finishing work to commence. Numerous installations and inspections occurred parallel to the panels: Rubberized membrane, insulation paneling, and gravel ballast for the flat roof; cables, plumbing, sprinkler pipes, fire retardant, and insulation; wall studs and hung ceiling frames; basement pipes and mechanical and electrical equipment; and guide rails and cabins for the elevators. The service elevator was finished first to transport interior finish materials. A material hoist on the outside of the building and a mobile crane were also used.

Finishes also included drywall, flooring or tiling, doors, counters, trim, and millwork. Light fixtures, faucets, sprinkler heads, and other hardware were installed after painting the walls. The sequence was dictated by the layering of components and to prevent damage to already finished work. The penthouse required concrete framing, masonry block walls, installing and connecting conduits, waterproofing, placing gravel ballast, roof pavers, drains, hardware, insulation, painting, and trims.

The planned project duration (makespan) was 23 months. Milestones punctuated the schedule, including starts and finishes of placing concrete, above grade work, installing elevators, hanging drywall, enclosing the building envelope, providing electric power, and substantial completion. Work processes below and above grade differ significantly due to stabilizing and waterproofing the excavation. Except for the taller first floor, floors were identical with many repetitive tasks. The presence of the tower crane divided the execution into three phases. Its availability was kept to a minimum due to its high rental cost.

\section{SIMULATION MODEL DEVELOPMENT}

\subsubsection{Integrate Available Construction Project Data}

Initially the exact construction process had to be understood and available data had to be imported from their original files:

- Microsoft ${ }^{\circledR}$ Project data with task names, durations, and dependency converted from the contractor's Primavera files.

- $\quad$ Microsoft $^{\mathbb{B}}$ Excel data with resource names, capacities, and tasks manually transcribed from interviewing the staff.

Once an solid understanding of the raw data was established the two datasets were merged to produce coherent information for designing the simulation model. The key (and non-trivial) step in this merging was to identify the links of tasks and their resources. The results were then imported into an Excel file and formatted to align with the WorkSim ${ }^{\circledR}$ database. This compatible format also enables the consistent specification of different process constraints, e.g. task duration formulas, multiple types of precedence constraints, multiple types of task and resource dependencies, calendar constraints, and so forth. 


\subsubsection{Create Initial Simulation Model Using Process Templates}

Next the process data were manipulated and organized into a format that facilitated effective maintenance and reuse. Each project is called a "workload" in WorkSim ${ }^{\circledR}$. Based on the simulation objectives, an analyst may create multiple workloads with different priorities, start dates, resource teams, etc. to simulate several concurrent projects. Such resource-constrained multi-project analyses yield insight into the effects of shared resources, completion times, and time phased load balancing.

Process templates are an important concept for designing construction simulation models. A process template is a standardized set of tasks, resource requirements, and constraints for performing a logical group of tasks that occur repeatedly during projects. In essence, they are reusable building blocks that can be quickly combined and edited to form different workloads. A well designed set of process templates improves model management, maintainability, and reuse. In this case study, the authors created several process templates to represent recurring activity blocks such as site mobilization, foundation and excavation, basement structure, ground floor structure, above ground structure, precast installation and window fitting, basement finishes, above ground finishes, elevators, etc. Composing a simulation model of the overall process could then be accomplished by creating a blank new workload, selecting templates, and 'stitching' them together in the proper sequence. Figure 2 shows a simulation model fragment that is produced by the composition of a subset of these newly defined templates.

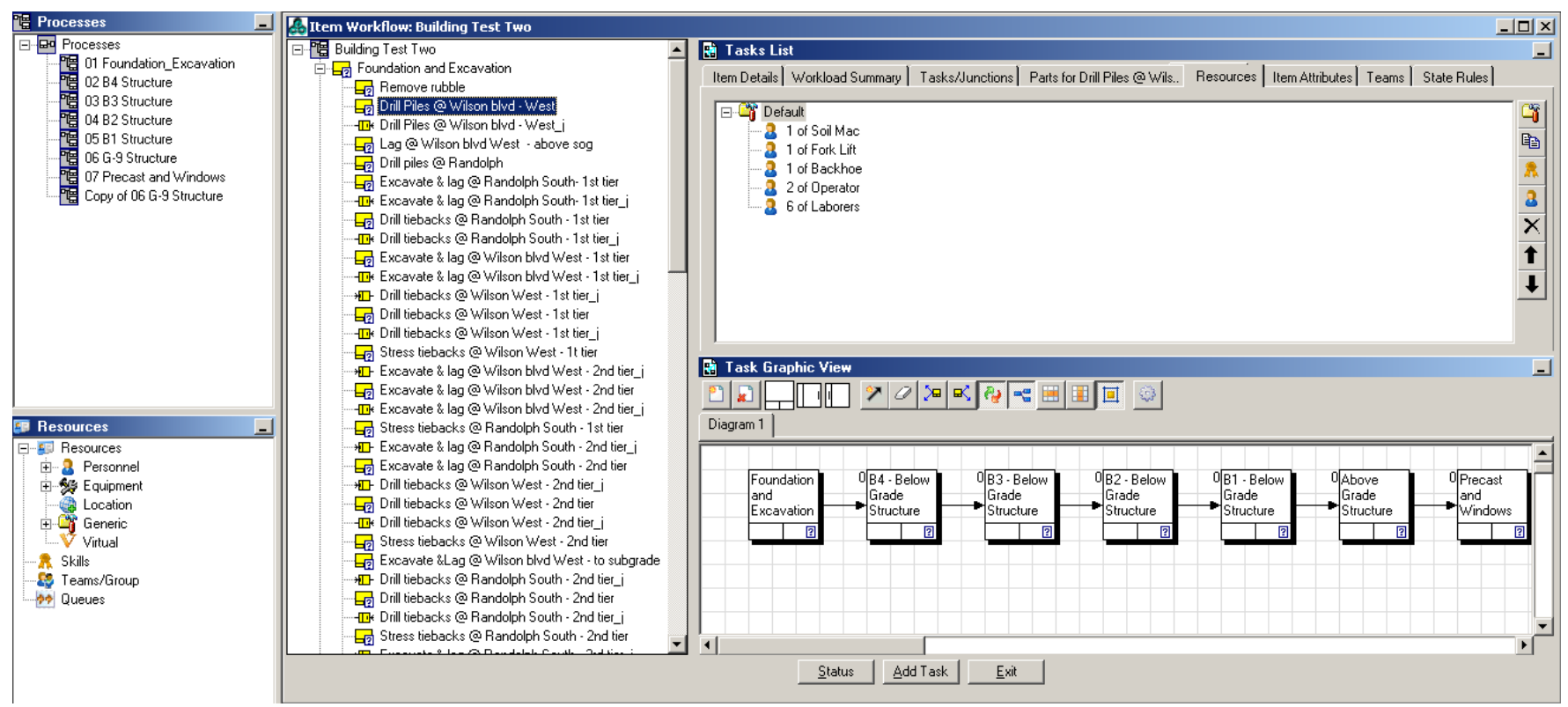

Figure 2: Process Templates: Building Blocks for Simulation Model Design

\subsubsection{Detail and Refine the Simulation Model}

Several factors and constraints must be considered in designing a simulation model. Constraint types can be temporal, resources, workspace, calendar, state, etc. Temporal constraints are predecessor-successor relationships that specify allowable a temporal order between tasks. Basic types include finish-to-start, start-to-start, start-to-finish, and finish-to-finish. These relationships can also be extended by a lag that specifies a required time delay between tasks. Such lags can be applied to all four different types of relationships. Precedence relationships are modeled in WorkSim ${ }^{\circledR}$ as direct links between tasks as shown in Figure 3. In this case study, data about such temporal constraints were directly imported from the available electronic files. 


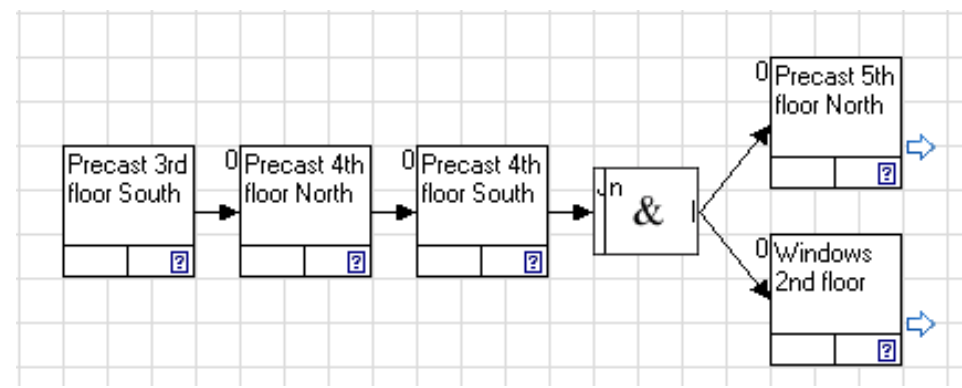

Figure 3: WorkSim ${ }^{\circledR}$ Model Precedence Relationship Display

Figure 3 shows that the task Precast $3^{\text {rd }}$ floor South must finished before task Precast $4^{\text {th }}$ floor North may start. It also shows an inter-process constraint where tasks Precast $5^{\text {th }}$ floor North and Windows $2^{\text {nd }}$ floor may start only after Precast $4^{\text {th }}$ floor South has been completed. Resource constraints specify quantities and types to perform a given task. For example, Precast $4^{\text {th }}$ floor South uses 1 mobile crane, 1 operator, 2 welding machines, 2 welders, and 5 iron workers as shown in Figure 4.

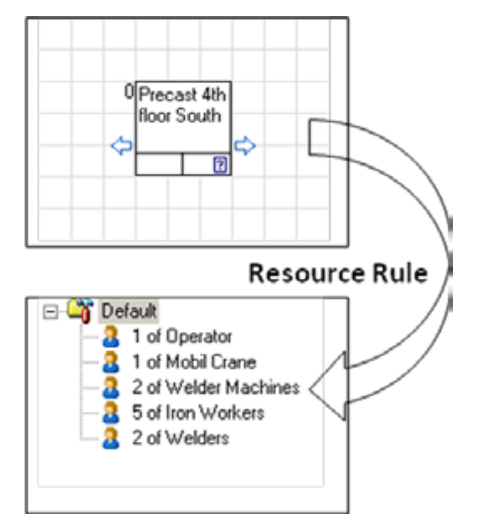

Figure 4: Resource Constraint Example

In this model, resource constraints were imported from the resource data file as described earlier. Other types of process constraints are e.g. the calendar, workspace, states, parts or materials, resource teams, etc. As shown in Figure 2, WorkSim ${ }^{\circledR}$, $s$ graphical user interface visualizes only portions of the model of interest to reduce drawing complexity, different from typical schedule network diagrams. Structured query language (SQL) queries can identify redundant constraint paths in the database.

An important distinction of a simulation model versus a schedule is its ability to use stochastic duration functions as opposed to deterministic (point estimate) durations. Simulation experiments can select durations from fitted distribution functions. This in turn produces a range of estimates for the overall project duration, or flow time. Modeling variability at the task level allows estimating the variability of the entire project. A normally distributed 'bell curve' will appear for a large number of runs. Estimates are often sought for specific confidence ranges, e.g. finding a $90 \%$ confidence interval for the flow time.

Thus for a meaningful estimate of the project variability, data on the variability of task durations and resource availabilities must be available or estimated, e.g. as probability distributions commonly associated with the construction activities (AbouRizk and Halpin 1992). In this case study, the subject matter expert indicated that a triangular distribution could be applied with a $5 \%$ reduction as the minimum and a $25 \%$ growth as the maximum. The authors also experimented with a lognormal distribution with several 'triangular' parameters to derive right skewed patterns for individual task duration estimates.

\subsection{Simulation Model Execution and Interpretation}

\subsubsection{Design and Execute Simulation Experiment}

Experimental design involves setting up simulation parameters and policies. Task selection governs how tasks are selected or prioritized during the execution of the simulation model. Several task selection policies were available for this case study: 
- Largest number of successors first: If several tasks that could be activated at one point in simulated time, this policy selects the task with the most successors to enable more parallel tasks to possibly reduce the flow time of the project.

- Shortest processing time first: This policy selects the task with the shortest duration from several possible ones.

- Longest processing time: This policy selects the task with the longest duration from several possible ones.

- User-specified priority: This policy selects the task with the highest priority from several possible ones.

Other parameters include setting up the time horizon, creating a random number seed, specifying the number of replications, setting up trace options, etc. Another issue of experimental design is to determine which resource constraints may need to be relaxed. Some types of construction equipment in the case study e.g. had a limited availability while others were limited by the space constraint of the site itself. Moreover, operators were limited but laborers were not. Input from the subject matter experts was used to relax constraints in the simulation model only for those resources that could be acquired by the contracting company as needed. After all these simulation parameters had been specified, the model was ready to be executed.

\subsubsection{Perform Model Verification and Validation}

Verification means ensuring that the simulation model runs in the manner that was intended by the simulation analyst. It includes assessing the completeness and consistency of the model. Validation means ensuring that the simulation model is a good enough representation of reality relative to the purpose for which the model was designed. It involves running the model and assessing the trace data and outputs in terms of their adequacy relative to the real-world project being represented.

The simulation model is run and trace reports are studied for verification and validation. This attempts to identify logical flaws in the model. For example, the resource rule of task A might call for 15 carpenters, while the resource pool may only contain a total available number of 12 carpenters. WorkSim ${ }^{\circledR}$ identifies such discrepancies in its error warning log that can then be used to correct the model. Discrepancies are resolved iteratively until the model is deemed consistent and complete.

\subsubsection{Generate and Interpret Simulation Results}

Results from simulation runs are saved to a database. The tool can generate different types of reports as shown in Figure 5.

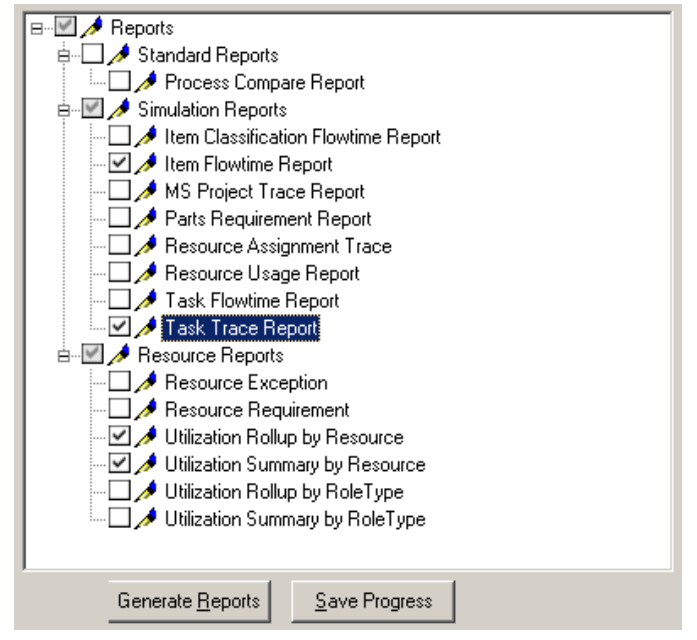

Figure 5: WorkSim ${ }^{\circledR}$ Report Types

For this case study the authors generated the item flow time report as shown in Figure 6, the utilization summary, and the utilization rollup report. As specific objectives the authors chose to estimate the flow time and its variability for completing the above grade structure with weekly varying resource requirement for laborers and finishers in the months of June and July.

\begin{tabular}{|l|c|c|r|r|r|r|r|}
\hline & Flowtime (in Days) & \multicolumn{1}{c|}{$95 \%$} \\
Item Name & Type & Days & Min. Value & Max. Value & Std. Dev. & $\begin{array}{c}95 \% \\
\text { Confidence }\end{array}$ & $\begin{array}{c}99 \\
\text { Confidence }\end{array}$ \\
\hline G-9 Test & None & 131.4 & 112.8 & 157.0 & 12.5 & \pm 4.77 & \pm 5.88 \\
\hline
\end{tabular}

Figure 6: Example Flow Time Report 
The flow time report shows the average, minimum, and maximum flow time for completing the above grade structure. As explained earlier, the simulation tool considers the variability in the task duration to estimate the variability of project. Standard deviation is an estimate of variability. The report contains the $95 \%$ and $99 \%$ confidence intervals for the average flow time. Figure 7 shows the weekly varying resource requirements for laborers and finishers in form of a histogram report.
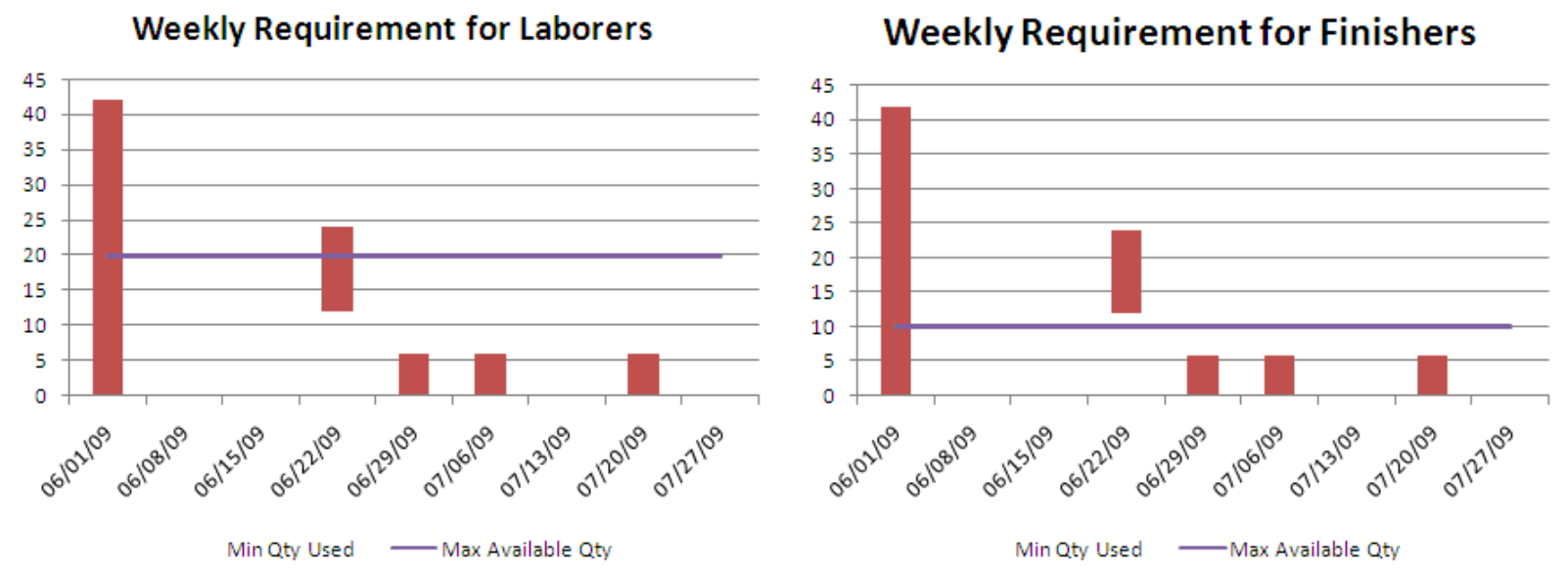

Figure 7: Time Varying Resource Requirements Report

This resource requirement report provides time-phased values for resources in the model. It clearly indicates the weeks when demand exceeds availability as marked with a blue line. For simulating longer time horizons one could generate monthly or quarterly resource requirements for long-term planning. This section has only discussed one process of the Work$\mathrm{Sim}^{\circledR}$ model to illustrate its usefulness for the construction industry. The full model contained the entire construction project.

\section{RESULTS AND CONCLUSIONS}

\subsection{Summary}

This paper has described a knowledge based approach that seeks to motivate the increased application of simulation technology within the construction industry. The premise of this approach is that practitioners will able to use existing processrelated data from their schedules as inputs to create a functioning simulation model with little or no user intervention. It concluded with a case study of a real project to illustrate its 1 application and potential benefits. It is the authors' hope that their ideas will support an increased effort to harness the power of simulation technology for construction management problems.

\subsection{Implementation Challenges}

While the level of detail of the schedule necessarily the same as the simulation model, the analytical capabilities of the latter are broader and open new opportunities for detailed and dynamic experimentation to support planning and decision making.

\subsection{Recommendations for Future Research}

Areas that provide opportunity for beneficial research and development that continues this approach include the design and development of knowledge models and templates for simulation applications in construction management; the application of data mining and knowledge discovery methods to facilitate cost effective design and analysis of simulation models; methods to integrate real-time construction execution data with construction planning and simulation tools; and integration of simulation technology with other decision support and planning systems such as e.g. (a) cost estimating, (b) design and engineering analysis support, (c) construction scheduling, (d) constructions materials management, and (e) enterprise resource planning. 
Lucko, Swaminathan, Benjamin and Madden

\section{ACKNOWLEDGEMENT}

The authors wish to express their gratitude to the anonymous construction contracting company that agreed to provide the data for this research and especially to their managerial staff who kindly shared their time and answered the many questions.

\section{REFERENCES}

Aalami, F. B. 1998. Using construction method models to generate 4D production models. Dissertation, Department of Civil and Environmental Engineering, Stanford University, Stanford, California.

AbouRizk, S. M., and D. W. Halpin. 1992. Statistical properties of construction duration data. Journal of Construction Engineering and Management 118(3): 525-544.

Akbaş, R. 2003. Geometry-based modeling and simulation of construction processes. Dissertation, Department of Civil and Environmental Engineering, Stanford University, Stanford, California.

$\mathrm{Au}, \mathrm{G}$, and R. J. Paul. 1994. Graphical simulation model specification based on activity cycle diagrams. Computers and Industrial Engineering 26(2): 295-306.

Benjamin, P. C., D. Delen, and M. Erraguntla. 1998. An introduction to using PROSIM for business process simulation and analysis. In Proceedings of the 1998 Winter Simulation Conference, ed. Medeiros, D. J., Watson, E. F., Carson, J. S., and Manivannan, M. S., Washington, District of Columbia, December 13-16, 1998, 315-321, Piscataway, New Jersey: Institute of Electrical and Electronics Engineers, Inc.

Benjamin, P. C., M. Patki, and R. Mayer. 2006. Using ontologies for simulation modeling. In Proceedings of the 2006 Winter Simulation Conference, ed. Perrone, L. F., Wieland, F. P., Liu, J., Lawson, B. G., Nicol, D. M., and Fujimoto, R. M., Monterey, California, December 3-6, 2006, 1151-1159, Piscataway, New Jersey: Institute of Electrical and Electronics Engineers, Inc.

Bonnal, P., D. Gourc, and G. Lacoste. 2002. The life cycle of technical projects. Project Management Journal 33(1): 12-19.

Bureau of Economic Analysis 2008. Industry economic accounts: Gross-domestic-product-by-industry-accounts: Custom data selection. U.S. Department of Commerce, Washington, District of Columbia, Available via <http://www.bea.gov/industry/gpotables/gpo_action.cfm?anon=75779\&table_id=22079\& format_type $=0>$ [accessed August 5, 2008].

Bureau of Labor Statistics 2008. Career Guide to Industries: Construction. 2008-09 Edition. U.S. Department of Labor, Washington, District of Columbia, Available via $<\mathrm{http}: / / \mathrm{stats.bls.gov/oco/cg/cgs003.htm>} \mathrm{[accessed}$ August 5, 2008].

Cates, G. R., M. J. Steele, M. Mollaghasemi, and G. Rabadi. 2002. Modeling the space shuttle. In Proceedings of the 2002 Winter Simulation Conference, ed. Yücesan, E., Chen, C.-H., Snowdon, J. L., and Charnes, J. M., San Diego, California, December 8-11, 2002, 754-762, Piscataway, New Jersey: Institute of Electrical and Electronics Engineers, Inc.

Cates, G. R., and M. Mollaghasemi. 2005. A discrete event simulation model for assembling the international space station. In Proceedings of the 2005 Winter Simulation Conference, ed. Kuhl, M. E., Steiger, N. M., Armstrong, F. B., and Joines, J. A., Orlando, Florida, December 4-7, 2005, 1260-1264, Piscataway, New Jersey: Institute of Electrical and Electronics Engineers, Inc.

Chang, D. Y.-M. 1986. RESQUE: A resource based simulation system for construction process planning. Dissertation, Department of Civil Engineering, University of Michigan, Ann Arbor, Michigan.

Fischer, M. A, and C. K. Kam. 2002. Product model \& 4D CAD - final report. CIFE Technical Report \#143, October, 2002, Center for Integrated Facility Engineering, Department of Civil and Environmental Engineering, Stanford University, Stanford, California.

Fondahl, J. W. 1962. A non-computer approach to the critical path method for the construction industry. $2^{\text {nd }}$ ed., November 1961, Technical Report No. 9, Revised 1962, Prepared under Research Contract NBy-17798, Bureau of Yards and Docks, U.S. Navy, Distributed by The Construction Institute, Stanford University, Stanford, California.

Froese, T. M. 1992. Integrated computer-aided project management through standard object-oriented models. Dissertation, Department of Civil Engineering, Stanford University, Stanford, California.

Galloway, P. D. 2006a. Comparative study of university courses on critical-path method scheduling. Journal of Construction Engineering and Management 132(7): 712-722.

Galloway, P. D. 2006b. Survey of the construction industry relative to the use of CPM scheduling for construction projects. Journal of Construction Engineering and Management 132(7): 697-711.

Ioannou, P. G., and J. C. Martínez. 1996. Simulation of complex construction processes. In Proceedings of the 1996 Winter Simulation Conference, ed. Brunner, D. T., Swain, J. J., Charnes, J. M., and Morrice, D. J., Coronado, California, December 8-11, 1996, 1321-1328, Piscataway, New Jersey: Institute of Electrical and Electronics Engineers, Inc. 
Halpin, D. W. 1973. An investigation of the use of simulation networks for modeling construction operations. Dissertation, Department of Civil Engineering, University of Illinois, Urbana-Champaign, Illinois.

Haney v. United States, 676 F.2d 584 (Ct. Cl. 1982).

Hassan, M. M., and S. Gruber. 2008. Simulation of concrete paving operations on Interstate-74. Journal of Construction Engineering and Management 134(1): 2-9.

Kamat, V. R. 2003. VITASCOPE: Extensible and scalable 3D visualization of simulated construction operations. Dissertation, Department of Civil and Environmental Engineering, Virginia Polytechnic Institute and State University, Blacksburg, Virginia.

Kamat, V. R., and S. El-Tawil. 2007. Evaluation of augmented reality for rapid assessment of earthquake-induced building damage. Journal of Computing in Civil Engineering 21(5): 303-310.

Karhu, V. 2001. A generic construction process modelling method: A model based approach for process description. Dissertation, Division of Construction Management and Economics, Royal Institute of Technology, Stockholm, Sweden.

Kelley, J. E., and M. R. Walker. 1959. Critical path planning and scheduling. In Proceedings of the Eastern Joint Computer Conference. Boston, MA, December 1-3, 1959, (16): 160-173, New York, New York: National Joint Computer Committee, Association for Computing Machinery.

Lee, G. 2004. A new formal and analytical process to product modeling (PPM) method and its application to the precast concrete industry. Dissertation, College of Architecture, Georgia Institute of Technology, Atlanta, Georgia.

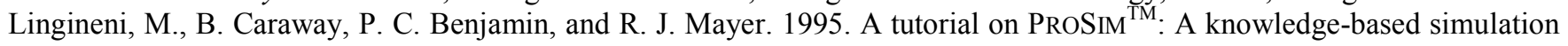
model design tool. In Proceedings of the 1995 Winter Simulation Conference, ed. Alexopoulos, C., Kang, K., Lilegdon, W. R., and Goldsman, D., Arlington, Virginia, December 3-6, 1995, 408-412, Piscataway, New Jersey: Institute of Electrical and Electronics Engineers, Inc.

Liu, L.-Y. 1991. COOPS - construction object-oriented process simulation system. Dissertation, Department of Civil Engineering, University of Michigan, Ann Arbor, Michigan.

Lucko, G., P. C. Benjamin, and M. G. Madden. 2008. Harnessing the power of simulation in the project management / decision support aspects of the construction industry. In Proceedings of the 2008 Winter Simulation Conference, ed. Mason, S. J., Hill, R., Mönch, L., and Rose, O., Miami, Florida, December 7-10, 2008, 2479-2487, Piscataway, New Jersey: Institute of Electrical and Electronics Engineers, Inc.

Madden, M. G., R. Wyrick, and D. E. O’Neill. 2005. A strategy for autogeneration of space shuttle ground processing simulation models for project makespan estimation. In Proceedings of the 2005 Winter Simulation Conference, ed. Kuhl, M. E., Steiger, N. M., Armstrong, F. B., and Joines, J. A., Orlando, Florida, December 4-7, 2005, 1251-1259, Piscataway, New Jersey: Institute of Electrical and Electronics Engineers, Inc.

Martínez, J. C. 1996. STROBOSCOPE: State and resource based simulation of construction processes. Dissertation, Department of Civil Engineering, University of Michigan, Ann Arbor, Michigan.

Mayer, R. J., M. K. Painter, and P. S. deWitte. (1992). IDEF family of methods for concurrent engineering and business reengineering applications. Report, Knowledge Based Systems, College Station, Texas, 77 p. Available via <http: / / www. idef. com/pdf/IDEFFAMI . pdf> [accessed January 24, 2009].

Odeh, A. M. 1992. CIPROS: Knowledge-based Construction Integrated Project and Process Planning Simulation System. Dissertation, Department of Civil Engineering, University of Michigan, Ann Arbor, Michigan.

Oldfather, P. M., A. S. Ginsberg, and H. M. Markowitz. 1966. Programming by questionnaire: How to construction a program generator. Rand Report RM-5129-PR, Santa Monica, California: Rand Corporation.

Paul, R. J., and S. T. Chew. 1987. Simulation modeling using an interactive simulation program generator. Journal of the Operational Research Society 38(8): 735-752.

Rekapalli, P. V., and J. C. Martínez. 2007. Enabling dynamic state control of discrete-event simulation models to enhance model validation. In Proceedings of the 2007 Construction Research Congress, ed. Chinowsky, P. S., Songer, A. D., and Carrillo, P. M., Grand Bahama Island, The Commonwealth of the Bahamas, May 6-8, 2007, 9 p., Reston, Virginia: American Society of Civil Engineers.

Steele, M. J., M. Mollaghasemi, and G. Rabadi. 2002. Generic simulation models of reusable launch vehicles. In Proceedings of the 2002 Winter Simulation Conference, ed. Yücesan, E., Chen, C.-H., Snowdon, J. L., and Charnes, J. M., San Diego, California, December 8-11, 2002, 747-753, Piscataway, New Jersey: Institute of Electrical and Electronics Engineers, Inc.

Son, Y. J., and R. A. Wysk. 2001. Automatic simulation model generation for simulation-based, real-time shop floor control. Computers in Industry 45(3): 291-308.

Tatum, C. B. 1988. Classification system for construction technology. Journal of Construction Engineering and Management 114(3): 344-363. 
Waller, A. P., and Ladbrook, J. 2002. Experiencing virtual factories of the future. In Proceedings of the 2002 Winter Simulation Conference, ed. Yücesan, E., Chen, C.-H., Snowdon, J. L., and Charnes, J. M., San Diego, California, December 811, 2002, 513-517, Piscataway, New Jersey: Institute of Electrical and Electronics Engineers, Inc.

Weaver, P. 2006. A brief history of scheduling: Back to the future. In Proceedings of the 2006 myPrimavera06 Conference, Canberra, Australia, April 4-6, 2006, Kingston, Australia: Primavera Australia, 10 p. Available via <http://www.pmforum.org/library/papers/2006/A_Brief_History_of_Scheduling.pdf> [accessed January 24, 2009].

Wickwire, J. M., and Ockman, S. 1999. Use of critical path method on contract claims - 2000. The Construction Lawyer 19(4): 12-21.

Yuan, Y., Dogan, C. A., and Viegelahn, G. L. 1993. A flexible simulation model generator. Computers and Industrial Engineering 24(2): 165-175.

Zayed, T. M., and Halpin, D. W. 2001. Simulation of concrete batch plant production. Journal of Construction Engineering and Management 127(2): 132-141.

Zayed, T. M., and Halpin, D. W. 2004. Simulation as a tool for pile productivity assessment. Journal of Construction Engineering and Management 130(3): 394-404.

\section{AUTHOR BIOGRAPHIES}

GUNNAR LUCKO is Assistant Professor of Civil Engineering and Director of the Construction Engineering and Management Program in the Department of Civil Engineering at the Catholic University of America. He holds a German Diploma in Civil and Environmental Engineering from Hamburg University of Technology and an M.S. and Ph.D. from Virginia Polytechnic Institute and State University. His research interests include mathematical representation, simulation, and analysis of schedules, construction equipment operations and economics, optimization methods, constructability analysis, and engineering education. He has studied statistical equipment valuation models, has participated in research for the Construction Industry Institute, and is currently working on schedule analysis research funded by the National Science Foundation. He is a member of ASCE and the INFORMS Simulation Society. His email is <lucko@cua.edu>.

KANNAN SWAMINATHAN is Senior Systems Analyst at KBSI where he leads the development of software systems to analyze, plan, schedule, and dispatch resources in process environments. He has over 15 years of experience in design, analysis and implementation of systems for government and commercial clients. His expertise include developing systems for simulation modeling and analysis, scheduling, planning, inventory control, and automated cash management. He has extensive experience in data modeling, process modeling, database design, simulation, and full life-cycle implementation of enterprise systems. He has an M.S. in Industrial Engineering from Texas A\&M University. Previously, he was a principal consultant with PricewaterhouseCoopers, LLP where he served as the lead consultant for a number of projects ranging from custom applications to eBusiness systems. His email is <kswaminathane kbsi.com>.

PERAKATH C. BENJAMIN as Vice President for Research and Development at KBSI directs its research and development activities. In that role, he manages and actively participate in the analysis, design, and development of advanced solutions for clients including the U.S. Department of Defense, NASA, and large corporations in the private industry. Several of the advanced technology solutions that were developed under his supervision are being applied extensively throughout industry and government. Dr. Benjamin has a Ph.D. in Industrial Engineering from Texas A\&M (1991). Prior to becoming a vice president at KBSI, he was a visiting assistant professor of Industrial Engineering and lead researcher at the Knowledge Based Systems Laboratory at Texas A\&M University. Dr. Benjamin has over 40 publications and book articles. He has delivered simulation and semantic technology consulting and training to multiple large organizations over the past 15 years. His email is <pbenjamin@kbsi.com>.

MICHAEL G. MADDEN is President and Senior Consultant at M. Madden Consulting, LLC, a Ph.D. Student in the University of Miami's Industrial Engineering Program, and a former Senior Vehicle Engineer for space shuttles Endeavour and Atlantis where he worked with the processing team and the test team responsible for technical decisions of the space shuttle process. He now works in the Florida Program Office of United Space Alliance, LLC where he develops simulation and datamining technology for estimating processing flows. He has an M.S. in Technology Management from Embry-Riddle Aeronautical University, and a BS-MET from Wentworth Institute of Technology. His research interests are in the resourceconstrained scheduling domain, especially in using criticality indices for heuristics, and in operations research problems associated with space shuttle processing and knowledge management. He is a member of IEEE, ACGIH, AIChE, and the INFORMS Simulation Society. His email is <mmadden. consultingegmail.com>. 